Article

\title{
Singlet Oxygen in Antimicrobial Photodynamic Therapy: Photosensitizer-Dependent Production and Decay in $E$. coli
}

Xavier Ragàs ${ }^{1}$, Xin He ${ }^{1}$, Montserrat Agut ${ }^{1}$, Mónica Roxo-Rosa ${ }^{2,3}$, António Rocha Gonsalves ${ }^{4}$, Arménio C. Serra ${ }^{4}$ and Santi Nonell ${ }^{1, *}$

1 Grup d'Enginyeria Molecular, Institut Químic de Sarrià, Universitat Ramon Llull, Barcelona E-08017, Spain; E-Mails: xavierragasa@iqs.url.edu (X.R.); xin.x.he@gmail.com (X.H.); montserrat.agut@iqs.url.edu (M.A.)

2 Center for Biodiversity, Functional \& Integrative Genomics, Faculty of Sciences, University of Lisbon, Lisbon 1749-016, Portugal

3 Department of Genetics, National Institute of Health Dr. Ricardo Jorge, Lisbon 1649-016, Portugal; E-Mail: roxorosa@hotmail.com

4 Departamento de Quimica, Universidade de Coimbra, Coimbra P-3049535, Portugal; E-Mails: arg@qui.uc.pt (A.R.G.); armenio.serra@gmail.com (A.C.S.)

* Author to whom correspondence should be addressed; E-Mail: santi.nonell@iqs.url.edu; Tel.: +34-93-267-2000; Fax: +34-93-205-6266.

Received: 25 January 2013; in revised form: 19 February 2013 / Accepted: 21 February 2013 / Published: 28 February 2013

\begin{abstract}
Several families of photosensitizers are currently being scrutinized for antimicrobial photodynamic therapy applications. Differences in physical and photochemical properties can lead to different localization patterns as well as differences in singlet oxygen production and decay when the photosensitizers are taken up by bacterial cells. We have examined the production and fate of singlet oxygen in Escherichia coli upon photosensitization with three structurally-different cationic photosensitizers, namely New Methylene Blue $\mathrm{N}$ (NMB), a member of the phenothiazine family, ACS268, a hydrophobic porphyrin with a single cationic alkyl chain, and zinc(II)-tetramethyltetrapyridinoporphyrazinium salt, a phthalocyanine-like photosensitizer with four positive charges on the macrocycle core. The kinetics of singlet oxygen production and decay indicate different localization for the three photosensitizers, whereby NMB appears to localize in an aqueous-like microenvironment, whereas ACS268 localizes in an oxygen-shielded site, highly reactive towards singlet oxygen. The tetracationic zinc(II) tetrapyridinoporphyrazine is extensively aggregated in the bacteria and fails to produce any detectable singlet oxygen.
\end{abstract}


Keywords: antimicrobial photodynamic therapy; cationic photosensitizers; E. coli; kinetics; photodynamic inactivation; singlet oxygen; time-resolved near-IR spectroscopy

\section{Introduction}

Antimicrobial photodynamic therapy (APDT) [1] has been shown as a viable alternative to the use of antibiotics against microbial pathogens, even to those that have developed resistance [2,3]. Briefly, the combination of a drug, usually referred to as the photosensitizer (PS), light and molecular oxygen leads to the production of reactive oxygen species (ROS), via electron or energy transfer (type I or type II reactions, respectively) from the triplet excited-state of the PS to molecular oxygen [4].

Many different PSs have been used over the years as antimicrobial agents in APDT $[5,6]$. Nowadays, the most effective ones are cationic at physiological $\mathrm{pH}$, e.g., phenothiazines, porphyrins and phthalocyanines [7-9]. These PSs exhibit high efficiency against microbial cells, especially against Gram-negative bacteria, due to the negative net charge found in the microbial cell walls of the latter [10-12].

In a previous study we reported how, by means of a combination of spectroscopic and time-resolved photophysical techniques, it is possible to understand where the PS localizes and how singlet oxygen $\left({ }^{1} \mathrm{O}_{2}\right)$, one of the reactive oxygen species that plays a major role in APDT [13], is produced and reacts with oxidizable biomolecules in its nearest environment. In that case, tetra- $N$-methylpyridylporphyrin (TMPyP) was used as a model, demonstrating a double localization both inside and outside the cell, and the ability of ${ }^{1} \mathrm{O}_{2}$ to cross the cell wall and react with the external aqueous media [14].

Figure 1. Chemical structures of the photosensitizers used in the study: NMB: New Methylene Blue N; ZnTMPyPz: zinc tetramethyltetrapyridino[3,4-b:39,49-g:30,40-1:3-,4q]porphyrazinium salt; ACS268: 5,10,15-tris(2,6-dichlorophenyl)-20-[N-(12-trimethyl ammonium chloride)-dodecyl- $p$-sulphonamidophenyl]porphyrin.

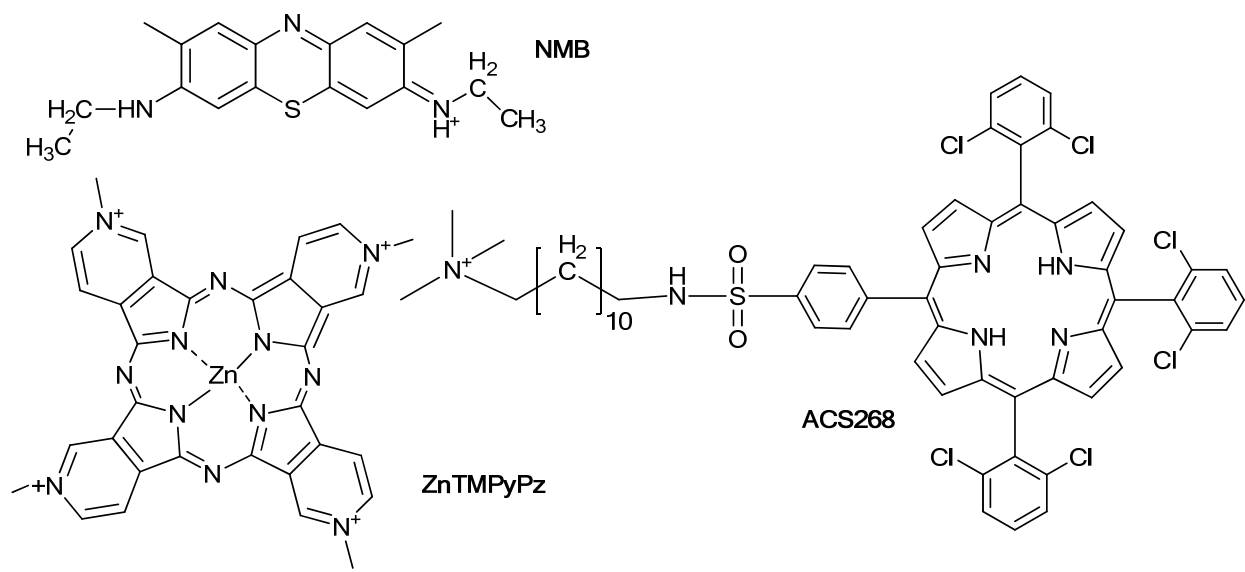

In this paper we report the differences in the kinetics of ${ }^{1} \mathrm{O}_{2}$ production and decay in Escherichia coli upon photosensitization with three different cationic PSs chosen as representative members of the aforementioned families, i.e., the phenothiazine New Methylene Blue N (NMB), a hydrophobic porphyrin with a cationic alkyl chain (ACS268), and a tetracationic zinc(II) pyridine-porphyrazine, namely zinc(II) 
tetramethyltetrapyridino[3,4-b:39,49-g:30,40-1:3-,4-q]porphyrazinium salt (ZnTMPyPz) (Figure 1). NMB and ZnTMPyPz are efficient antimicrobial photodynamic agents in vitro [15-18], whereas ACS268 is inactive against $E$. coli, although it shows some activity against $S$. aureus.

Aside from their cationic charges, each PS possesses different physical, chemical, and photophysical properties [6]. These variations should likely lead to a different PS localization and therefore, to a different microenvironment. It may therefore be insightful to study the details of ${ }^{1} \mathrm{O}_{2}$ photosensitization by different PSs to better understand the structure-activity relationships of different families of PS.

\section{Results and Discussion}

\subsection{PSs Binding to E. coli}

The uptake of NMB and ACS268 was studied by treating the cells with $\mathrm{NaOH} 0.1 \mathrm{M} / 1 \%$ sodium dodecyl sulphate (SDS) in order to extract the cell-bound PSs and analysing the cell lysates by fluorescence spectroscopy. Bulk concentrations of $10 \mu \mathrm{M}$ and $7.5 \mu \mathrm{M}$ were used, respectively. While the uptake of ACS268 reaches a plateau value after only $1 \mathrm{~h}$, the uptake of NMB requires $c a .20 \mathrm{~h}$ for completion (see Supplementary Information). For ZnTMPyPz we adopted the uptake conditions described by Dupouy et al. [15], namely 30 min contact time at $37^{\circ} \mathrm{C}$ and $10 \mu \mathrm{M}$ bulk concentration.

It was critical in our experiments to eliminate any PS molecule from the external aqueous buffer in order to ensure that all the spectroscopic data was related to cell-bound molecules. Therefore, to unmistakably assign the spectroscopic data, the external aqueous solutions were routinely tested before and after the in vitro measurements, providing no significant signal in all cases.

The absorption spectrum of NMB bound to E. coli showed a red-shift of $8 \mathrm{~nm}$ relative to that in the buffer (Figure 2A), as well as a slight change in the relative amplitudes of the band and the shoulder. However, no significant change was observed in the fluorescence emission spectrum (Figure 2B). For ZnTMPyPz, the absorption spectra both in E. coli and buffer showed a similar structureless broad-band distinct from the spectrum obtained in DMF, where it is in a monomeric form (Figure 2C). A $5 \mathrm{~nm}$ red shift was observed in the fluorescence spectrum relative to that in DMF (Figure 2D). For ACS268, the absorption spectrum in E. coli showed a $7 \mathrm{~nm}$ red shift relative to that in buffer (Figure 2E). The fluorescence spectra in $E$. coli and buffer showed similar structures but with a $5 \mathrm{~nm}$ red shift (Figure 2F).

Time-resolved fluorescence measurements provided additional insight on the uptake of the PSs (see Electronic Supplementary Information). The fluorescence of NMB at $657 \mathrm{~nm}$ decayed with first-order kinetics with a lifetime of $0.5 \pm 0.1 \mathrm{~ns}$ both in $E$. coli and in buffer. The fluorescence decay of ZnTMPyPZz in E. coli at 675 was also fitted with a single exponential function with a lifetime of $2.8 \pm 0.5 \mathrm{~ns}$. An additional exponential term was necessary to fit the data in buffer, namely with a lifetime of $0.5 \pm 0.1 \mathrm{~ns}$. Time-resolved fluorescence of ACS268 was inconclusive as the kinetics in solution was too complex to be fitted by any standard model. 
Figure 2. (A,C,E) Absorption and (B, D,F) fluorescence spectra of: $(\mathbf{A}, \mathbf{B})$ New Methylene Blue $\mathrm{N}$ in E. coli (solid line), PBS (dashed line), 1\% SDS in $0.1 \mathrm{M} \mathrm{NaOH}$ (dotted line). (C,D) ZnTMPyPz in E. coli (solid line), PBS (dashed line), DMF (dotted line). (E,F) ACS268 in E. coli (solid line), PBS (dashed line), DMF (dotted line).

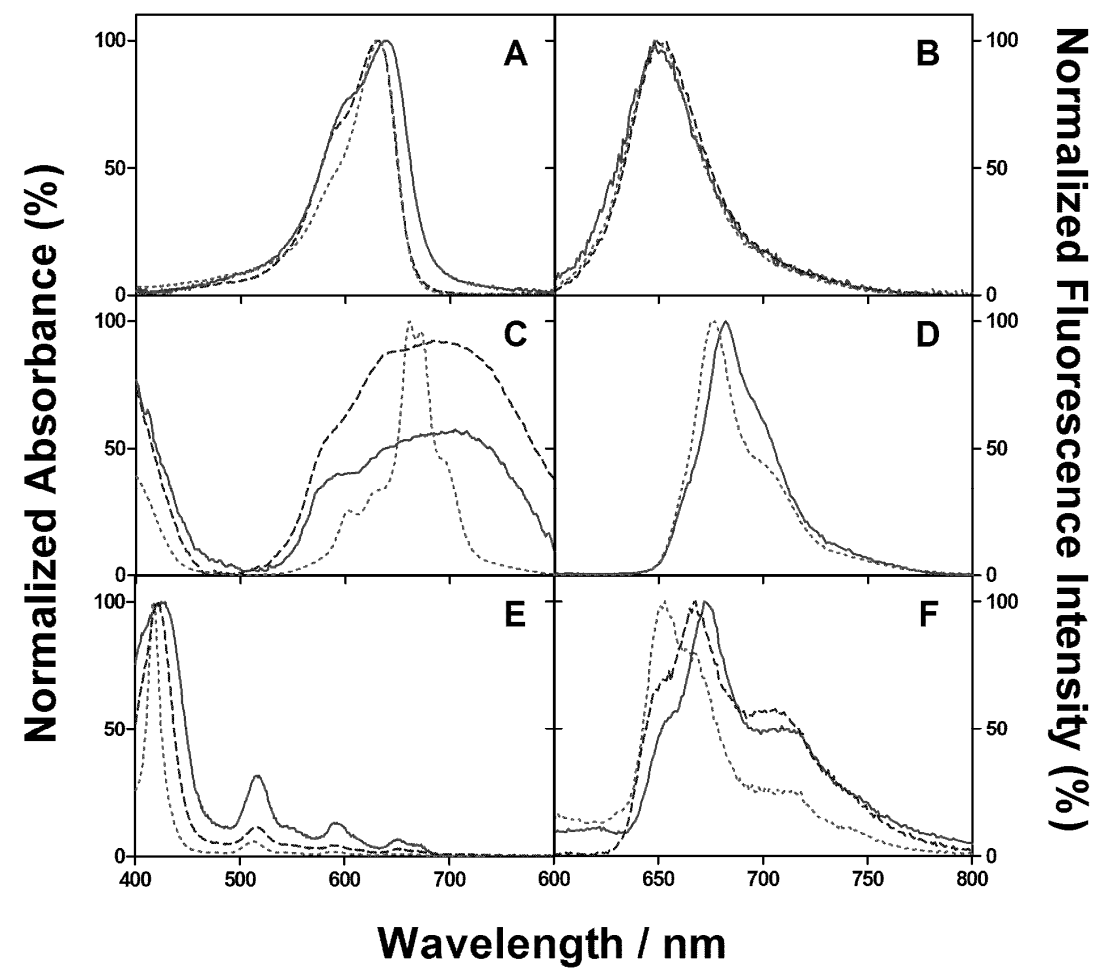

\subsection{Singlet Oxygen Kinetics in E. coli Cells with NMB as PS}

Pulsed-laser irradiation of NMB-loaded E. coli cells (30 min contact time; $10 \mu \mathrm{M}$ NMB bulk concentration) suspended in buffer at $\mathrm{pH} 7.4$ produced clear time-resolved ${ }^{1} \mathrm{O}_{2}$ phosphorescence signals at 1,270 $\mathrm{nm}$ (Figure 3). The contact time between the NMB solution and the bacteria had no effect on the ${ }^{1} \mathrm{O}_{2}$ luminescence kinetics. In PBS, the signals grew with a time constant of $\tau_{1}{ }^{\mathrm{PBS}}=2.5 \pm 1 \mu \mathrm{s}$, and decayed monoexponentially with a lifetime $\tau_{2}{ }^{\text {PBS }}=3.7 \pm 1 \mu \mathrm{s}$. In deuterated-PBS (D-PBS), the signal rise remained unchanged with a lifetime $\tau_{1}{ }^{\mathrm{D}-\mathrm{PBS}}=2.5 \pm 1 \mu \mathrm{s}$, but it decayed more slowly, with a time constant of $\tau_{2}{ }^{\mathrm{D}-\mathrm{PBS}}=65 \pm 2 \mu \mathrm{s}$. Addition of $0.75 \mathrm{mM}$ bovine serum albumin (BSA), a ${ }^{1} \mathrm{O}_{2}$ quencher that is not able to cross the cell wall due to its size [19], clearly modified the signal: the rise of the phosphorescence was now complete within the time resolution of our set-up, and the decay was also faster with lifetime $\tau_{1}{ }^{\text {BSA }}=7.0 \pm 1 \mu$ s. Saturation of this suspension with oxygen led to a further decrease of the decay lifetime to $\tau_{1}{ }^{\mathrm{BSA}, \mathrm{O} 2}=3.5 \pm 1 \mu \mathrm{s}$. Finally, measurements in $E$. coli spheroplasts, i.e., bacteria from which the cell wall had been almost completely removed, led to a 4-fold decrease in the ${ }^{1} \mathrm{O}_{2}$ phosphorescence signal intensity, but with the same kinetics as in intact cells (see Supplementary Information). 
Figure 3. Singlet oxygen phosphorescence at $1270 \mathrm{~nm}$ using NMB as photosensitizer in (A) E. coli/PBS in air-saturated atmosphere, (B) E. coli/D-PBS in air-saturated atmosphere, (C) E. coli/D-PBS + $0.75 \mathrm{mM}$ BSA in air-saturated atmosphere. (D) E. coli/D-PBS +0.75 mM BSA in oxygen-saturated atmosphere.

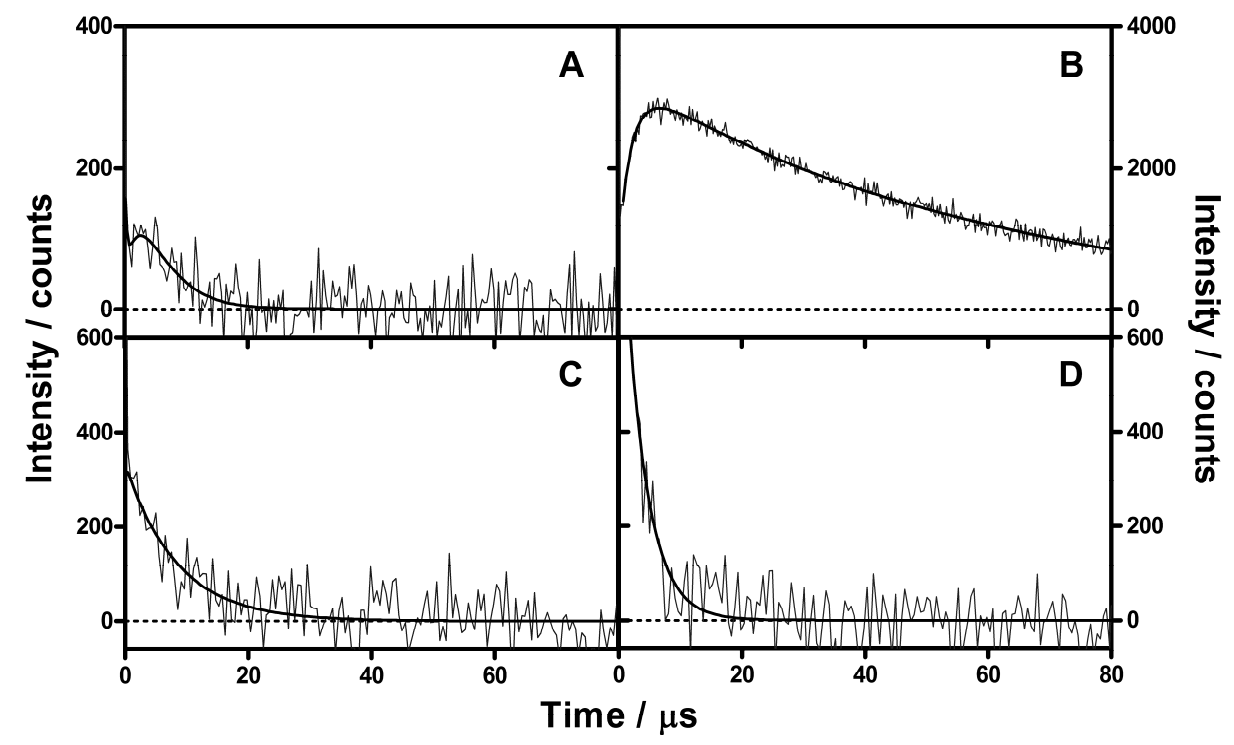

\subsection{Singlet Oxygen Kinetics in E. coli Cells with ZnTMPyPz as PS}

Although ZnTMPyPz is a potent ${ }^{1} \mathrm{O}_{2}$ photosensitizer in solution [20], irradiation of ZnTMPyPz-loaded E. coli cells suspended in D-PBS did not produce any clear time-resolved ${ }^{1} \mathrm{O}_{2}$ phosphorescence signal at $1,270 \mathrm{~nm}$ (see Supplementary Information). Neither a higher contact time of ZnTMPyPz (3 h), nor a higher acquisition time of the ${ }^{1} \mathrm{O}_{2}$ phosphorescence signal (12 million laser pulses) produced any detectable signal.

\subsection{Singlet Oxygen Kinetics in E. coli Cells with ACS268 as PS}

The quantum yield of singlet oxygen production $\left(\Phi_{\Delta}\right)$ of ACS268 was measured in two different solvents, DMF and $\mathrm{D}_{2} \mathrm{O}$, by comparison of the signal produced by optically-matched solutions of reference PSs (phenalenone and TMPyP) [21] with that produced by ACS268. The detailed procedure is described in the Supplementary Information. Thus, $\Phi_{\Delta}$ values of $0.87 \pm 0.01$ and $0.04 \pm 0.01$ were determined in DMF and $\mathrm{D}_{2} \mathrm{O}$, respectively. Irradiation of ACS268-loaded E. coli cells produced time-resolved ${ }^{1} \mathrm{O}_{2}$ phosphorescence signals clearly different from those observed for NMB (Figure 4). In PBS, the signals grew with a time constant of $\tau_{1}{ }^{\mathrm{PBS}}=2.1 \pm 1 \mu \mathrm{s}$, and decayed biexponentially with lifetimes $\tau_{2}{ }^{\mathrm{PBS}}=8.6 \pm 1 \mu \mathrm{s}$ and $\tau_{3}{ }^{\mathrm{PBS}}=34.1 \pm 1 \mu \mathrm{s}$. In D-PBS, the rise of the signal was slightly slower, $\tau_{1}{ }^{\mathrm{D}-\mathrm{PBS}}=5.2 \pm 1 \mu \mathrm{s}$, but the decay kinetics remained unchanged biexponential. Addition of $0.75 \mathrm{mM}$ of BSA shortened only the slowest decay lifetime, i.e., $\tau_{2}{ }^{\mathrm{BSA}}=8.6 \pm 1 \mu \mathrm{s}$ and $\tau_{3}{ }^{\mathrm{BSA}}=34.0 \pm 1 \mu \mathrm{s}$. Finally, measurements in E. coli spheroplasts led to a 3-fold decrease in the ${ }^{1} \mathrm{O}_{2}$ phosphorescence signal intensity, but with the same kinetics as in intact cells (see Supplementary Information). 
Figure 4. Singlet oxygen phosphorescence at $1270 \mathrm{~nm}$ using ACS268 as photosensitizer in (A) E. coli/PBS in air-saturated atmosphere, (B) E. coli/D-PBS in air-saturated atmosphere, (C) E. coli/D-PBS + $0.75 \mathrm{mM}$ BSA in air-saturated atmosphere.

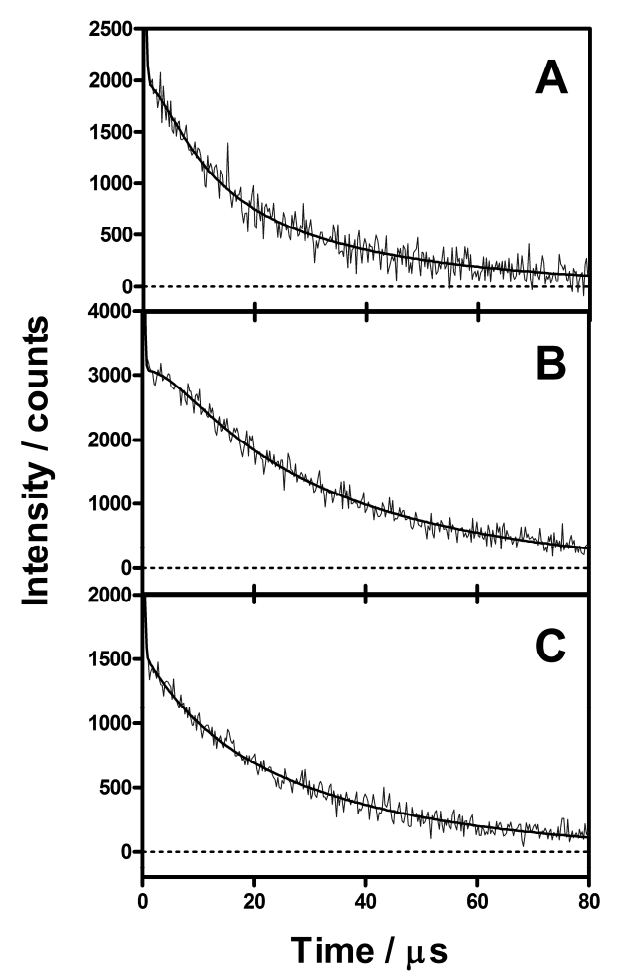

\subsection{Discussion}

The main goal of this study was to gain insight into the kinetics of ${ }^{1} \mathrm{O}_{2}$ production and decay by three different photosensitizers in E. coli cells, thereby shedding light on the mechanism of photodynamic inactivation of Gram-negative bacteria. Specifically, we were interested to learn whether representative members of three different families of photosensitizers would provide different photosensitization kinetics.

Towards this goal, it was first essential to obtain unambiguous time-resolved ${ }^{1} \mathrm{O}_{2}$ phosphorescence signals from viable cells, i.e., (1) to reduce to a minimum the acquisition time as the ${ }^{1} \mathrm{O}_{2}$ kinetics in cells changes with increasing light exposure [22,23], and (2) to identify the optimal concentration and contact time of each PS for efficient cell binding/uptake. A concentration $c a .10 \mu \mathrm{M}$, similar to those used in inactivation experiments for E. coli [15,24], and a 30 min contact time, typical in APDT [25,26], proved adequate in this respect notwithstanding the higher amount of NMB taken up at longer contact times (Figure 2). Under similar experimental conditions, all these PSs show no significant dark toxicity $[15,17]$.

In homogeneous environments, the ${ }^{1} \mathrm{O}_{2}$ signals can be appropriately described by Equation (1), where $S_{0}$ is a quantity proportional to the amount of ${ }^{1} \mathrm{O}_{2}$ formed upon pulse excitation, $\tau_{\mathrm{T}}$ is the lifetime of the PS's triplet-excited state, and $\tau_{\Delta}$ is the ${ }^{1} \mathrm{O}_{2}$ lifetime. Thus, the signal is expected to show two monoexponential components, corresponding to the rise and decay of the signal:

$$
S_{t}=S_{0} \frac{\tau_{\Delta}}{\tau_{\Delta}-\tau_{\mathrm{T}}}\left[\exp \left(-t / \tau_{\Delta}\right)-\exp \left(-t / \tau_{\mathrm{T}}\right)\right]
$$


In microheterogeneous environments it is often found that different populations the PS's triplet-excited state and ${ }^{1} \mathrm{O}_{2}$ exist and therefore Equation (1) must be expanded to account for such different populations Equation (2). In such cases the rise and the decay of the signals follow multiexponential laws, the number of exponentials representing the number of independent populations.

$$
S_{t}=\sum_{i}\left\{S_{0},_{i} \frac{\tau_{\Delta, i}}{\tau_{\Delta, i}-\tau_{\mathrm{T}, i}}\left[\exp \left(-t / \tau_{\Delta, i}\right)-\exp \left(-t / \tau_{\mathrm{T}, i}\right)\right]\right\}
$$

The kinetic models may be even more complex due to phenomena such as diffusion or cross-talk between the different populations.

Regarding the phenothiazine group, NMB was chosen as the model due to its highest singlet oxygen quantum yield and higher hydrophobicity [27], as well as its ability to properly inactivate many bacterial species [27]. Two major changes can be observed in the absorption spectrum of NMB upon binding to E. coli: on one hand, the relative contribution of the shoulder at $600 \mathrm{~nm}$ increases, which is consistent with the report by Usacheva et al. [28] that phenothiazine dyes tend to dimerize in the presence of bacteria. On the other, the band maximum shows a slight red shift that reveals a change in the NMB's microenvironment [29]. Somewhat surprisingly, such microenvironmental changes have no effect on the fluorescence spectrum or in the fluorescence lifetime. The fact that there is no change in the fluorescence lifetime indicates that, despite the different microenvironment, NMB is still surrounded by water molecules (see Supplementary Information). This conclusion is supported by the ${ }^{1} \mathrm{O}_{2}$ phosphorescence formation and decay kinetics. Both in PBS and D-PBS, the lifetimes obtained for the ${ }^{1} \mathrm{O}_{2}$ phosphorescence signal matched those obtained in neat $\mathrm{H}_{2} \mathrm{O}$ or $\mathrm{D}_{2} \mathrm{O}$, a $2.5 \mu$ s rise component assigned to the triplet state of $\mathrm{NMB}$, and a 3.7 or $65 \mu$ s component due to ${ }^{1} \mathrm{O}_{2}$, respectively. This indicates that $\mathrm{NMB}$ is localized in an aqueous-like environment and that ${ }^{1} \mathrm{O}_{2}$ is deactivated mainly by interactions with $\mathrm{H}_{2} \mathrm{O}$ or $\mathrm{D}_{2} \mathrm{O}$ [30]. Of course, it cannot be excluded that another fraction of ${ }^{1} \mathrm{O}_{2}$ molecules reacts with or is quenched by cell components so rapidly that it does not contribute to the observed signal. Care was taken to ensure that the signals did not originate on NMB molecules that have leaked into the bulk solution during the experiments. The supernatant solution was checked before and after the experiments and in all cases we could find no signal. Addition of BSA to the $\mathrm{D}_{2} \mathrm{O}$ suspensions significantly changed the signal kinetics, causing both a faster rise $(<1 \mu \mathrm{s})$ and a faster decay (lifetime of $7 \mu \mathrm{s}$ ) in air-saturated suspensions. The latter component was decreased further to 3.5 $\mu$ s upon bubbling with oxygen, which increased five-fold the concentration of oxygen in the system. These results suggest a dual effect of BSA: on one hand it quenches ${ }^{1} \mathrm{O}_{2}$ as one would expect [19] decreasing its lifetime below the time resolution of our setup; on the other, it interacts with NMB shielding it from oxygen [31], which effectively increases the triplet NMB lifetime from $2.5 \mu$ s to $7 \mu$ s (in air) or $3.5 \mu$ s (under oxygen) as the bimolecular energy transfer process is slowed down. Therefore, NMB must be located somewhere in the external structure of the cell wall, accessible to BSA, or must be able to relocate and bind to BSA upon its addition to the solution. This conclusion is consistent with Usacheva's et al. report that phenothiazinium dyes interact with the outer-wall bacterial lipopolysaccharides (LPS) [32,33]. Overall, our results are in line with the report that an initial population of $10^{4} \mathrm{CFU} \cdot \mathrm{mL}^{-1}$ of $E$. coli could be totally eliminated by a minimum lethal concentration 
of $7.8 \mu \mathrm{M} \mathrm{NMB}$ at a light fluence of $3.15 \mathrm{~J} \mathrm{~cm}^{-2}$ [17]. Thus the suggestion that ${ }^{1} \mathrm{O}_{2}$ plays an important role in the mechanism of action of NMB [17] is supported by our spectroscopic data.

Concerning the phthalocyanine family, ZnTMPyPz was chosen as a model since Dupouy et al. [15] had shown that, using the same uptake conditions as in this work, irradiation with visible light reduced the cell viability by $99.5 \%$. These results can now be rationalized in the light of our findings: First, as observed in the absorption spectrum (Figure 2C), ZnTMPyPz is largely aggregated in E. coli as deduced from the broadening of the bands relative to DMF. This aggregation would explain why no signal is observed in the ${ }^{1} \mathrm{O}_{2}$ luminescence experiments under conditions similar to those used for the other PSs, even increasing the contact time and the acquisition time. Spesia et al. showed that alterations in the cell membrane appear to be the major cause of E. coli inactivation upon APDT with visible light and a tetracationic zinc(II) phthalocyanine derivative $\left(\mathrm{ZnPc}^{4+}\right)$ [34]. Assuming that (1) ZnTMPyPz and $\mathrm{ZnPc}^{4+}$ localize in a similar microenvironment because of the structural similarity, and that (2) ZnTMPyPz is basically aggregated like in an aqueous media, as observed by the absorption spectrum and the absence of ${ }^{1} \mathrm{O}_{2}$ luminescence signal, a localization to the outer structure of the cell wall, comparable to the one obtained with NMB, is tentatively attributed. This conclusion is not contradictory to the $99.5 \%$ reduction in cell viability, as there is still a small quantity of monomer, detectable by steady-state (Figure 2D) and time-resolved (Figure S3; see the Supplementary Information) fluorescence measurements, that could be responsible for the production of ROS and the resulting photodynamic effect shown by ZnTMPyPz.

We previously demonstrated that a tetracationic porphyrin such as TMPyP, with the cationic charges peripherally-distributed, localizes in E. coli at two different sites: (1) externally bound to the cell wall, probably in a similar localization as NMB and ZnTMPyPz, and (2) inside the cell, bound to nucleic acids [14]. We hypothesize that ACS268, which has a unique cationic charge in the alkyl chain, would localize in a completely different environment than TMPyP, as the cationic charge is far away from the photoactive core and the lipophilicity/hydrophilicity of the molecule is completely different. The totally different $\Phi_{\Delta}$ values in DMF and $\mathrm{D}_{2} \mathrm{O}$ clearly demonstrate that ACS268 is able to produce ${ }^{1} \mathrm{O}_{2}$ only when it is in monomeric form.

Both the spectroscopic measurements and the ${ }^{1} \mathrm{O}_{2}$ phosphorescence in E. coli are in agreement with the aforementioned hypothesis. The red shift observed in the absorption and fluorescence spectra in E. coli indicates a different environment surrounding the PS relative to that in solution $[29,35,36]$.

With ACS268, two components with lifetimes $8.6 \mu$ s and $34 \mu$ s are observed in the ${ }^{1} \mathrm{O}_{2}$ phosphorescence experiments in PBS, D-PBS and upon addition of BSA. The presence of two lifetimes suggests two different localizations for ACS268 in E. coli., likely in the cell wall as deduced from the 3-fold decrease in the ${ }^{1} \mathrm{O}_{2}$ phosphorescence signal intensity observed in spheroplasts. Both ACS268 populations are clearly shielded from oxygen as evidenced by the long triplet lifetimes as compared to the $2.5 \mu$ s found for NMB. This in turn indicates that only a minor fraction of triplets is quenched by oxygen and therefore that the amount of ${ }^{1} \mathrm{O}_{2}$ produced by ACS269 in the cells must be very low. Moreover, the $\tau_{\Delta}$ values for ${ }^{1} \mathrm{O}_{2}$ in $E$. coli are significantly shorter $(2.1 \mu \mathrm{s}$ in PBS; $5.2 \mu$ s in D-PBS suspensions) than the ones observed in buffer (3.5 $\mu$ s in PBS; $67 \mu$ s in D-PBS) [30] indicating a fast deactivation of ${ }^{1} \mathrm{O}_{2}$ by quenchers surrounding the PS molecules that, however, does not lead to cell death. The inefficient production of singlet oxygen and its fast deactivation are consistent with the very low photodynamic activity found for this compound against E. coli (this work, data not shown). 
The rate constant of ${ }^{1} \mathrm{O}_{2}$ decay in microheterogeneous systems under exchange equilibrium conditions, $k_{\mathrm{d}}$, is described by Equation (3) [37]:

$$
k_{d}=\frac{1}{\tau_{\Delta}}=\frac{K_{e q} \cdot f_{m} \cdot k_{d, \text { cell }}+\left(1-f_{m}\right) \cdot k_{d, \text { water }}}{K_{e q} \cdot f_{m}+\left(1-f_{m}\right)}
$$

where $K_{e q}=\left[{ }^{1} \mathrm{O}_{2}\right]_{\text {cell }} /\left[{ }^{1} \mathrm{O}_{2}\right]_{\text {water }}$ is the partition equilibrium of ${ }^{1} \mathrm{O}_{2}$ between the two phases, $f_{m}$ and $\left(1-f_{m}\right)$ are the volume fractions of the cell and aqueous phase, respectively, and $k_{d, \text { cell }}$ and $k_{d, \text { water }}$ are the decay rate constants inside and outside the cell, respectively. Assuming $K_{e q} \approx 1$ and $f_{m} \approx 0.0012$ for our suspensions in $5 \times 10^{8} \mathrm{CFU} / \mathrm{mL}$, the lifetime of ${ }^{1} \mathrm{O}_{2}$ within the bacterial cell can be estimated as $\tau_{\Delta, \text { cell }} \approx 7 \mathrm{~ns}$, a value that would perfectly correlate with the ${ }^{1} \mathrm{O}_{2}$ phosphorescence kinetics observed upon addition of BSA, which traps any ${ }^{1} \mathrm{O}_{2}$ molecule escaping from the cell wall into the external aqueous media.

It has previously been demonstrated that the presence of external proteins clearly modifies the effectiveness of APDT to inactivate microbial cells [38-40]. Such effect can also be observed in the kinetics of ${ }^{1} \mathrm{O}_{2}$ in the presence of BSA. The addition of BSA clearly modifies the ${ }^{1} \mathrm{O}_{2}$ phosphorescence signal produced by NMB, decreasing $\tau_{\Delta}$ and increasing $\tau_{\mathrm{T}}$, demonstrating an interaction between NMB and BSA (Figure 3). However, the effect is barely observed when ACS268 is used as the PS (Figure 4), suggesting a deeper localization of ACS268 into the cell wall, thereby making it less accessible to BSA.

\section{Experimental}

\subsection{Chemicals}

New Methylene Blue N (NMB) was supplied by Sigma-Aldrich Co. (St. Louis, MO, USA). Zinctetramethyltetrapyridino[3,4-b:39,49-g:30,40-1:3-,4-q]porphyrazinium salt (ZnTMPyPz) was synthesized as described by Marti et al. [20]. 5,10,15-tris(2,6-Dichlorophenyl)-20-[N-(12-trimethylammonium chloride)-dodecyl-p-sulphonamidophenyl]porphyrin (ACS268) was synthesized as described in the Supplementary Information. Deuterium oxide $\left(\mathrm{D}_{2} \mathrm{O},>99.9 \%\right)$ and dimethylformamide were purchased from Solvents Documentation Synthesis (Peypin, France). Bovine serum albumin (98\%), lysozyme, sodium dodecyl sulphate (SDS), trizma, and Dubelcco's phosphate buffered saline (PBS) were purchased from Sigma-Aldrich Co. Saccarose and ethylendiamine tetraacetic acid (EDTA) were supplied by Panreac S.A. (Barcelona, Spain). Deuterated PBS (D-PBS) was prepared by dissolving PBS powder in $\mathrm{D}_{2} \mathrm{O}$ instead of $\mathrm{H}_{2} \mathrm{O}$.

\subsection{Bacterial Growth}

Escherichia coli CECT101 was grown overnight in Luria-Bertani (LB) media, then transferred into new LB media to obtain an initial optical density value of 0.1 per $\mathrm{cm}$ at $660 \mathrm{~nm}$, and allowed to grow aerobically at $37{ }^{\circ} \mathrm{C}$. Cells in the middle logarithmic phase (optical density 0.35 per $\mathrm{cm}$ at $660 \mathrm{~nm}$ ) were harvested by centrifugation $(10 \mathrm{~min}, 3,000 \mathrm{rpm})$ and then resuspended in sterile PBS at $\mathrm{pH}$ 7.4. The procedure was repeated three times, yielding a bacterial concentration of $10^{8}$ colony forming units (CFU) $\mathrm{mL}^{-1}$, as assessed by serial dilutions of the cell suspension followed by a colony formation assay. 


\subsection{PS Binding to E. coli}

The bacterial uptake of PS was determined by fluorescence spectroscopy following the procedure described by Hamblin et al. [26,41]. Bacterial suspensions $\left(10^{8} \mathrm{CFU} \cdot \mathrm{mL}^{-1}\right)$ were incubated in the dark at room temperature $(\mathrm{NMB}, \mathrm{ACS} 268)$ or at $37^{\circ} \mathrm{C}(\mathrm{ZnTMPyPz})$ with varying concentrations of PS and contact times under gentle stirring. Afterwards, the cells were washed by centrifugation (10 min, 3,000 rpm, 3 times) to remove any excess of PS. After the last centrifugation, a solution of $1 \%$ SDS in $0.1 \mathrm{M} \mathrm{NaOH}$ was added to the pellets and shaken for a minimum of $24 \mathrm{~h}$. Each experiment was repeated three times. Stock PS solutions were sterilized by filtration through a $0.22 \mu \mathrm{m}$ sterile filter and stored in the dark at $4{ }^{\circ} \mathrm{C}$ for a maximum of 1 week.

\subsection{Spheroplasts Formation}

Spheroplasts were obtained by resuspending treated or untreated E. coli cells in Tris- $\mathrm{HCl} 0.05 \mathrm{M}$ buffer at $\mathrm{pH}=6.8$ containing $0.01 \mathrm{M}$ EDTA, $0.3 \mathrm{M}$ sucrose and lysozyme $\left(1 \mathrm{mg} \mathrm{mL}{ }^{-1}\right)$ under stirring. After $1 \mathrm{~h}$ incubation at $37^{\circ} \mathrm{C}$, tubes were centrifuged twice at 2,000 rpm for $10 \mathrm{~min}$ [42]. The pellet was then resuspended in PBS solution at $\mathrm{pH}=7.4$. PS-loaded spheroplasts were obtained by first incubating whole $E$. coli cells with the PS and then subjecting them to the procedure above.

\subsection{General Spectroscopic Measurements}

Absorption spectra were recorded on a Cary 4E spectrophotometer (Varian, Palo Alto, CA, USA), equipped with a $110 \mathrm{~mm}$ diameter integrating sphere and high performance photomultiplier tube for transmittance measurements. Fluorescence emission spectra were recorded in a Spex Fluoromax-2 spectrofluorometer (Horiba Jobin-Yvon, Edison, NJ, USA). Fluorescence decays were recorded with a time-correlated single photon counting system (Fluotime 200, PicoQuant GmbH, Berlin, Germany) equipped with a red sensitive photomultiplier. Excitation was achieved by means of a $375 \mathrm{~nm}$ picosecond diode laser, or a 596 or $657 \mathrm{~nm}$ LED working at $10 \mathrm{MHz}$ repetition rate. The counting frequency was always below 1\%. Fluorescence decays were analysed using the PicoQuant FluoFit 4.0 data analysis software.

\subsection{Time-Resolved Singlet Oxygen Measurements}

${ }^{1} \mathrm{O}_{2}$ phosphorescence detected by means of a customized PicoQuant Fluotime 200 system described in detail elsewhere [43]. Briefly, a diode-pumped pulsed Nd:Yag laser (FTSS355-Q, Crystal Laser, Berlin, Germany) working at $10 \mathrm{kHz}$ repetition rate at $532 \mathrm{~nm}(12 \mathrm{~mW}, 1.2 \mu \mathrm{J}$ per pulse) was used for excitation. A 1,064 nm rugate notch filter (Edmund Optics, Barrington, NJ, USA) was placed at the exit port of the laser to remove any residual component of its fundamental emission in the near-IR region. The luminescence exiting from the side of the sample was filtered by a cold mirror (CVI Melles Griot, Albuquerque, NM, USA) to remove any scattered laser radiation, and focused on the entrance slit of a Science Tech 9055 dual grating monochromator. A near-IR sensitive photomultiplier tube assembly (H9170-45, Hamamatsu Photonics, Hamamatsu City, Japan) was used as detector at the exit port of the monochromator. Photon counting was achieved with a multichannel scaler (Becker\&Hickl MSA 300 or PicoQuant's Nanoharp 250). The system is similar to that used in other laboratories [44]. 
Time-resolved ${ }^{1} \mathrm{O}_{2}$ signals were analysed by fitting either Equation (1) or (2) to the data using the FluoFit software. The lifetime values quoted throughout the manuscript refer to mean and standard deviation values derived from at least three independent measurements. All spectroscopic measurements were carried out in 1-cm quartz cuvettes (Hellma, Müllheim, Germany) at room temperature.

\subsection{Measurements in Bacterial Suspensions}

In a typical experiment, bacterial suspensions were incubated in the dark with the desired amount of PS for a given period of time. The cells were then washed three times with PBS and resuspended in PBS to a final concentration of $\sim 5 \times 10^{8} \mathrm{CFU} \cdot \mathrm{mL}^{-1}$. For time-resolved phosphorescence measurements, the bacterial suspensions $(3 \mathrm{~mL})$ were irradiated with 3 million laser pulses at $532 \mathrm{~nm}$. The suspensions were gently stirred during the measurements. Appropriate controls were performed to ensure that the signals originated from PS molecules bound to the bacterial cells (see Supplementary Information).

\section{Conclusions}

In summary, we have demonstrated that, between the different families used in the study, there are remarkable differences in (1) the microenvironment surrounding the PSs, i.e., in their localization, and (2) the kinetics of production and decay of ${ }^{1} \mathrm{O}_{2}$. When bound to E. coli, NMB localizes in an aqueous-like microenvironment, accessible to external proteins such as BSA and interacting with the LPS in cell-wall, ZnTMPyPz might localize similarly to NMB, where it is almost completely aggregated, and ACS268 localizes in a deeper position of the external structure of the cell wall, namely in the outer membrane, shielded from oxygen as demonstrated with the triplet lifetimes. With regards to the initial location of ${ }^{1} \mathrm{O}_{2}$ produced by the PSs, ${ }^{1} \mathrm{O}_{2}$ generated by $\mathrm{NMB}$ can move freely within the cell being mainly deactivated by the aqueous phase, while a completely different scenario is observed for ACS268, suggesting that ${ }^{1} \mathrm{O}_{2}$ cannot escape freely from its primary site of production, and thus partially reacts with proximate cellular components. On the other hand, ZnTMPyPz did not show ${ }^{1} \mathrm{O}_{2}$-luminescence under conditions similar to those used for the others PSs, correlating with the lower photodynamic inactivation effect observed. Finally, the correlation between the spectroscopic results and the antimicrobial activity shown by these different photosensitizers indicates that the time-resolved monitoring of ${ }^{1} \mathrm{O}_{2}$ phosphorescence is a convenient tool to assess the efficiency of antimicrobial photodynamic treatments.

\section{Supplementary Materials}

Supplementary materials can be accessed at: http://www.mdpi.com/1420-3049/18/3/2712/s1.

\section{Acknowledgments}

This work was supported by grants of the Spanish Ministerio de Economía y Competitividad (CTQ2007-67763-C03-01/ BQU and CTQ2010-20870-C03-01). We also thank Chymiotechnon, Portugal, for financial and technical support. X.R. thanks the Generalitat de Catalunya and Fons Social Europeu for a predoctoral fellowship. X.H. thanks the support of MIT International Science and 
Technology Initiative Spain that made her involvement in this research possible. We are also indebted to T. Torres for providing us with a sample of the ZnTMPyPz compound.

\section{References}

1. Jori, G.; Fabris, C.; Soncin, M.; Ferro, S.; Coppellotti, O.; Dei, D.; Fantetti, L.; Chiti, G.; Roncucci, G. Photodynamic therapy in the treatment of microbial infections: Basic principles and perspective applications. Lasers Surg. Med. 2006, 38, 468-481.

2. Dai, T.; Huang, Y.Y.; Hamblin, M.R. Photodynamic therapy for localized infections - State of the art. Photodiagnosis Photodyn. Ther. 2009, 6, 170-188.

3. Wainwright, M. Photoantimicrobials-So what's stopping us? Photodiagnosis Photodyn. Ther. 2009, 6,167-169.

4. Schweitzer, C.; Schmidt, R. Physical mechanisms of generation and deactivation of singlet oxygen. Chem. Rev. 2003, 103, 1685-1757.

5. Garland, M.J.; Cassidy, C.M.; Woolfson, D.; Donnelly, R.F. Designing photosensitizers for photodynamic therapy: Strategies, challenges and promising developments. Future Med. Chem. 2009, 1, 667-691.

6. Wainwright, M. Photodynamic antimicrobial chemotherapy (PACT). J. Antimicrob. Chemother. 1998, 42, 13-28.

7. Bertoloni, G.; Rossi, F.; Valduga, G.; Jori, G.; Ali, H.; Vanlier, J.E. Photosensitizing activity of water-soluble and lipid-soluble phthalocyanines on prokaryotic and eukaryotic microbial-cells. Microbios 1992, 71, 33-46.

8. Nitzan, Y.; Gutterman, M.; Malik, Z.; Ehrenberg, B. Inactivation of gram-negative bacteria by photosensitized porphyrins. Photochem. Photobiol. 1992, 55, 89-96.

9. Romanova, N.A.; Brovko, L.Y.; Moore, L.; Pometun, E.; Savitsky, A.P.; Ugarova, N.N.; Griffiths, M.W. Assessment of photodynamic destruction of Escherichia coli O157:H7 and Listeria monocytogenes by using ATP bioluminescence. Appl. Environ. Microbiol. 2003, 69, 6393-6398.

10. Merchat, M.; Bertolini, G.; Giacomini, P.; Villanueva, A.; Jori, G. Meso-substituted cationic porphyrins as efficient photosensitizers of gram-positive and gram-negative bacteria. J. Photochem. Photobiol. B Biol. 1996, 32, 153-157.

11. Minnock, A.; Vernon, D.I.; Schofield, J.; Griffiths, J.; Parish, J.H.; Brown, S.B. Photoinactivation of bacteria. Use of a cationic water-soluble zinc phthalocyanine to photoinactivate both gram-negative and gram-positive bacteria. J. Photochem. Photobiol. B Biol. 1996, 32, 159-164.

12. Wainwright, M.; Phoenix, D.A.; Marland, J.; Wareing, D.R.A.; Bolton, F.J. A study of photobactericidal activity in the phenothiazinium series. FEMS Immunol. Med. Microbiol. 1997, $19,75-80$.

13. Ergaieg, K.; Chevanne, M.; Cillard, J.; Seux, R. Involvement of both type I and type II mechanisms in gram-positive and gram-negative bacteria photosensitization by a meso-substituted cationic porphyrin. Sol. Energy 2008, 82, 1107-1117.

14. Ragàs, X.; Agut, M.; Nonell, S. Singlet oxygen in E. coli: New insights for antimicrobial photodynamic therapy. Free Radic. Biol. Med. 2010, 49, 770-776. 
15. Dupouy, E.A.; Lazzeri, D.; Durantini, E.N. Photodynamic activity of cationic and non-charged $\mathrm{Zn}(\mathrm{II})$ tetrapyridinoporphyrazine derivatives: Biological consequences in human erythrocytes and Escherichia coli. Photochem. Photobiol. Sci. 2004, 3, 992-998.

16. Peleg, A.Y. Optimizing therapy for Acinetobacter baumannii. Semin. Respir. Crit. Care Med. 2007, 28, 662-671.

17. Phoenix, D.A.; Sayed, Z.; Hussain, S.; Harris, F.; Wainwright, M. The phototoxicity of phenothiazinium derivatives against Escherichia coli and Staphylococcus aureus. FEMS Immunol. Med. Microbiol. 2003, 39, 17-22.

18. Ragàs, X.; Dai, T.; Tegos, G.P.; Agut, M.; Nonell, S.; Hamblin, M.R. Photodynamic inactivation of Acinetobacter baumannii using phenothiazinium dyes: In vitro and in vivo studies. Lasers Surg. Med. 2010, 42, 384-390.

19. Snyder, J.W.; Skovsen, E.; Lambert, J.D.C.; Ogilby, P.R. Subcellular, time-resolved studies of singlet oxygen in single cells. J. Am. Chem. Soc. 2005, 127, 14558-14559.

20. Martí, C.; Nonell, S.; Nicolau, M.; Torres, T. Photophysical properties of neutral and cationic tetrapyridinoporphyrazines. Photochem. Photobiol. 2000, 71, 53-59.

21. Redmond, R.W.; Gamlin, J.N. A compilation of singlet oxygen yields from biologically relevant molecules. Photochem. Photobiol. 1999, 70, 391-475.

22. Kuimova, M.K.; Botchway, S.W.; Parker, A.W.; Balaz, M.; Collins, H.A.; Anderson, H.L.; Suhling, K.; Ogilby, P.R. Imaging intracellular viscosity of a single cell during photoinduced cell death. Nat. Chem. 2009, 1, 69-73.

23. Schlothauer, J.; Hackbarth, S.; Roder, B. A new benchmark for time-resolved detection of singlet oxygen luminescence-Revealing the evolution of lifetime in living cells with low dose illumination. Laser Phys. Lett. 2009, 6, 216-221.

24. Harris, F.; Chatfield, L.K.; Phoenix, D.A. Phenothiazinium based photosensitisers-Photodynamic agents with a multiplicity of cellular targets and clinical applications. Curr. Drug Targets 2005, 6, $615-627$.

25. Caminos, D.A.; Spesia, M.B.; Durantini, E.N. Photodynamic inactivation of Escherichia coli by novel meso-substituted porphyrins by 4 -(3- $N, N, N$-trimethylammoniumpropoxy)phenyl and 4-(trifluoromethyl)phenyl groups. Photochem. Photobiol. Sci. 2006, 5, 56-65.

26. Hamblin, M.R.; O’Donnell, D.A.; Murthy, N.; Rajagopalan, K.; Michaud, N.; Sherwood, M.E.; Hasan, T. Polycationic photosensitizer conjugates: Effects of chain length and gram classification on the photodynamic inactivation of bacteria. J. Antimicrob. Chemother. 2002, 49, 941-951.

27. Phoenix, D.A.; Harris, F. Phenothiazinium-based photosensitizers: Antibacterials of the future? Trends Mol. Med. 2003, 9, 283-285.

28. Usacheva, M.N.; Teichert, M.C.; Biel, M.A. The role of the methylene blue and toluidine blue monomers and dimers in the photoinactivation of bacteria. J. Photochem. Photobiol. B Biol. 2003, 71, 87-98.

29. Chirvony, V.S. Primary photoprocesses in cationic 5,10,15,20-meso-tetrakis(4- $N$-methylpyridiniumyl) porphyrin and its transition metal complexes bound with nucleic acids. J. Porphyrins Phthalocyanines 2003, 7, 766-774.

30. Rodgers, M.A.J. Solvent-induced deactivation of singlet oxygen-Additivity relationships in non-aromatic solvents. J. Am. Chem. Soc. 1983, 105, 6201-6205. 
31. Borissevitch, I.E.; Tominaga, T.T.; Schmitt, C.C. Photophysical studies on the interaction of two water-soluble porphyrins with bovine serum albumin. Effects upon the porphyrin triplet state characteristics. J. Photochem. Photobiol. A Chem. 1998, 114, 201-207.

32. Usacheva, M.N.; Teichert, M.C.; Biel, M.A. The interaction of lipopolysaccharides with phenothiazine dyes. Lasers Surg. Med. 2003, 33, 311-319.

33. Usacheva, M.N.; Teichert, M.C.; Sievert, C.E.; Biel, M.A. Effect of $\mathrm{Ca}^{2+}$ on the photobactericidal efficacy of methylene blue and toluidine blue against gram-negative bacteria and the dye affinity for lipopolysaccharides. Lasers Surg. Med. 2006, 38, 946-954.

34. Spesia, M.B.; Caminos, D.A.; Pons, P.; Durantini, E.N. Mechanistic insight of the photodynamic inactivation of Escherichia coli by a tetracationic zinc(II) phthalocyanine derivative. Photodiagn. Photodyn. Ther. 2009, 6, 52-61.

35. De Paoli, V.M.; de Paoli, S.H.; Borissevitch, L.E.; Tedesco, A.C. Fluorescence lifetime and quantum yield of TMPyPH2 associated with micelles and DNA. J. Alloys Compd. 2002, 344, $27-31$.

36. Lee, S.; Lee, Y.A.; Lee, H.M.; Lee, J.Y.; Kim, D.H.; Kim, S.K. Rotation of periphery methylpyridine of meso-tetrakis $(n-N$-methylpyridiniumyl)porphyrin $(\mathrm{n}=2,3,4)$ and its selective binding to native and synthetic DNAs. Biophys. J. 2002, 83, 371-381.

37. Lee, P.C.; Rodgers, M.A.J. Singlet molecular-oxygen in micellar systems: Distribution equilibria between hydrophobic and hydrophilic compartments. J. Phys. Chem. 1983, 87, 4894-4898.

38. Demidova, T.N.; Hamblin, M.R. Photodynamic therapy targeted to pathogens. Int. J. Immunopathol. Pharmacol. 2004, 17, 245-254.

39. Nitzan, Y.; Balzam-Sudakevitz, A.; Ashkenazi, H. Eradication of Acinetobacter baumannii by photosensitized agents in vitro. J. Photochem. Photobiol. B Biol. 1998, 42, 211-218.

40. Wilson, M.; Pratten, J. Lethal photosensitization of Staphylococcus aureus in-vitro-Effect of growth-phase, serum, and preirradation time. Lasers Surg. Med. 1995, 16, 272-276.

41. Demidova, T.N.; Hamblin, M.R. Effect of cell-photo sensitizer binding and cell density on microbial photoinactivation. Antimicrob. Agents Chemother. 2005, 49, 2329-2335.

42. Merchat, M.; Spikes, J.D.; Bertoloni, G.; Jori, G. Studies on the mechanism of bacteria photosensitization by meso-substituted cationic porphyrins. J. Photochem. Photobiol. B Biol. 1996, 35, 149-157.

43. Jimenez-Banzo, A.; Ragàs, X.; Kapusta, P.; Nonell, S. Time-resolved methods in biophysics. 7. Photon counting vs. analog time-resolved singlet oxygen phosphorescence detection. Photochem. Photobiol. Sci. 2008, 7, 1003-1010.

44. Maisch, T.; Baier, J.; Franz, B.; Maier, M.; Landthaler, M.; Szeimies, R.M.; Bäumler, W. The role of singlet oxygen and oxygen concentration in photodynamic inactivation of bacteria. Proc. Natl. Acad. Sci. USA 2007, 104, 7223-7228.

Sample Availability: Samples of the compound ACS268 is available from the authors.

(C) 2013 by the authors; licensee MDPI, Basel, Switzerland. This article is an open access article distributed under the terms and conditions of the Creative Commons Attribution license (http://creativecommons.org/licenses/by/3.0/). 